\title{
Frankenstein de Mary Shelley, o Filme: Um recurso para introdução da História da Ciência no Ensino de Ciências na visão de graduandos
}

\author{
André Silva dos Reis \\ Maria Dulcimar de Brito Silva
}

\section{Resumo}

Este estudo visa analisar o filme Frankenstein de Mary Shelley a partir da visão de graduandos, para que o mesmo venha a ser empregado como recurso midiático para uma abordagem introdutória da História da Ciência no ensino. Para tanto, oito monitores de Química do Centro de Ciências e Planetário, graduandos de licenciatura em Química, assistiram ao filme, em seguida, realizaram uma sinopse e, posteriormente, e responderam a um questionário. As respostas apontaram que o filme consegue transpor a ideia do que era ser um cientista e como a Ciência se desenvolvia. Pontuam também vários temas que podem ser levantados pelos professores relacionados ao papel da ciência na sociedade. Isso mostra como mídias visuais são recursos dinâmicos para uma abordagem introdutória, visto que, além de narrar os fatos, fica gravado na mente dos alunos a impressão visual de como a ciência foi desenvolvida ao longo dos séculos.

Palavras-chave: História da Ciência; Ensino de Ciências; Recurso didático.

\begin{abstract}
This study aims to analyze the film Frankenstein from undergraduate vision, so that it will be used as a media resource for an introductory approach to the History of Science in teaching. Therefore, eight trainees of Chemical Sciences and Planetary Center, undergraduate students in chemistry, watched the film, and then held a synopsis and then answered a questionnaire. The answers showed that the film manages to transpose the idea of what was to be a scientist and a science developed. Also punctuate several issues that can be raised by teachers related to the role of science in society. This shows how visual media are dynamic resources for an introductory approach view that in addition to narrating the facts is engraved in the minds of students the visual impression of how science has developed over the centuries.
\end{abstract}

Keywords: History of Science; Science Teaching; Teaching resource.

\section{INTRODUÇÃO}

Uma das maneiras que o professor pode recorrer para otimizar a aprendizagem dos conteúdos de ciências é trazer para a sala de aula o processo de construção do conhecimento cientifico por meio da História da Ciência. O emprego desse tema nas aulas permite criar uma base para a compreensão das teorias, visto que os estudos se darão desde o surgimento, perpassando por toda a trajetória até chegar nos conhecimentos vistos atualmente no Ensino de Ciências. Segundo Ferreira \& Ferreira1, a carência do conhecimento da História da Ciência traz como consequência o desânimo da juventude perante os conteúdos de ensino em geral, desenvolvendo o seu desejo em não aprender.

Mostrar ao aluno o conhecimento científico como um fruto de ações humanas em vez de empregá-lo como algo pronto e acabado, leva à construção de uma intimidade da Ciência com os

\footnotetext{
${ }^{1}$ A. M. P Ferreira \& M. E. M. P. Ferreira, "A História da Ciência na Formação de Professores," História da Ciência e Ensino: Construindo Interfaces 2 (2010): 1-13, http://revistas.pucsp.br/index.php/hcensino/article/view/2904 (acessado em 27 de março de 2016).
} 
pensamentos dos alunos. De acordo com Kavalek et al. ${ }^{2}$, a grande maioria dos docentes preocupa-se em conhecer e orientar os educandos em relação aos conceitos, porém, não deveriam apenas trabalhar em suas aulas conceitos, teorias, fenômenos, mas, sim, a história desses acontecimentos e quais as questões filosóficas envolvidas nesses contextos, assim como suas consequências.

Uma das formas iniciais de empregar a História da Ciência dentro das aulas é utilizar como recurso os filmes comerciais que possuam em seu enredo representações de fatos e de contextos que venham descrever como determinado conhecimento surgiu. Andrade ${ }^{3}$ aborda que a análise do conteúdo de alguns filmes mostra a capacidade de serem usados como recurso didático, fazendo a correlação dos conhecimentos que devem ser construídos pelos alunos com exemplos contidos nos mesmos. Souza \& Guimarães ${ }^{4}$ também pontuam o potencial dos filmes por trazerem informações, conceitos e significados que estão relacionados a um contexto histórico e social, atuando na transformação e manutenção de determinados significados.

Nesse sentido, o objetivo deste estudo foi adotar uma produção cinematográfica que possuísse elementos relacionados à História da Ciência para que possa ser usado como recurso didático para professores de Ciências.

Por essa razão, o filme "Frankenstein de Mary Shelley" , de 1994, foi adotado para avaliação como recurso didático no emprego da História da Ciência no Ensino de Ciências, sendo analisado por oito monitores em formação do Centro de Ciências e Planetário do Pará, graduandos do Curso de Licenciatura Plena em Ciências Naturais com habilitação em Química da Universidade do Estado do Pará. Após a exibição do filme foi solicitado que produzissem uma sinopse focando quais pontos eles conseguiam perceber os conhecimentos científicos empregados. Por fim, responderam a um questionário contendo questões abertas relacionadas ao tema, em que avaliaram e expuseram a visão que obtiveram do filme como uma ferramenta midiática para a introdução da História da Ciência nas disciplinas de Ciências.

\section{Frankenstein ou o Moderno Prometeu}

O filme é baseado na obra clássica de terror, intitulado primeiramente "Frankenstein ou 0 Moderno Prometeu", sendo a única obra literária da autora Mary Shelley publicada em 1818 (figura 1). Em sua narrativa conta a trajetória do médico Victor Frankenstein na busca pela imortalidade, que tem

\footnotetext{
2 D. S. Kavalek et al., "Filosofia e História da Química para Educadores em Química," História da Ciência e Ensino: Construindo Interfaces 12 (2015): 1-13, http://revistas.pucsp.br/index.php/hcensino/article/view/21917 (acessado em 27 de março de 2016).

3 A. C. Andrade, "Filmes Comerciais como Recurso Didático no Ensino de Ciências" (Monografia, Universidade do Estado do Rio de Janeiro, Instituto de Biologia Roberto Alcantara Gomes, 2010), 32 f.http://www.educadores.diaadia.pr.gov.br/arquivos/File/fevereiro2013/ciencias_artigos/monografia_filmes_comerciais.pdf (acessado em 26 de março de 2016).

4 F. R. Souza \& L. B. Guimarães, "Filmes nas Salas de Aula: As Ciências em Foco," Textura no 28 (2013): 99-110, http://www.periodicos.ulbra.br/index.php/txra/article/view/927 (acessado em 29 de março de 2016).
} 
como pano de fundo os elementos da Ciência daquele período como o galvanismo, o uso ilegal de cadáveres em estudos e vivissecções 5 .

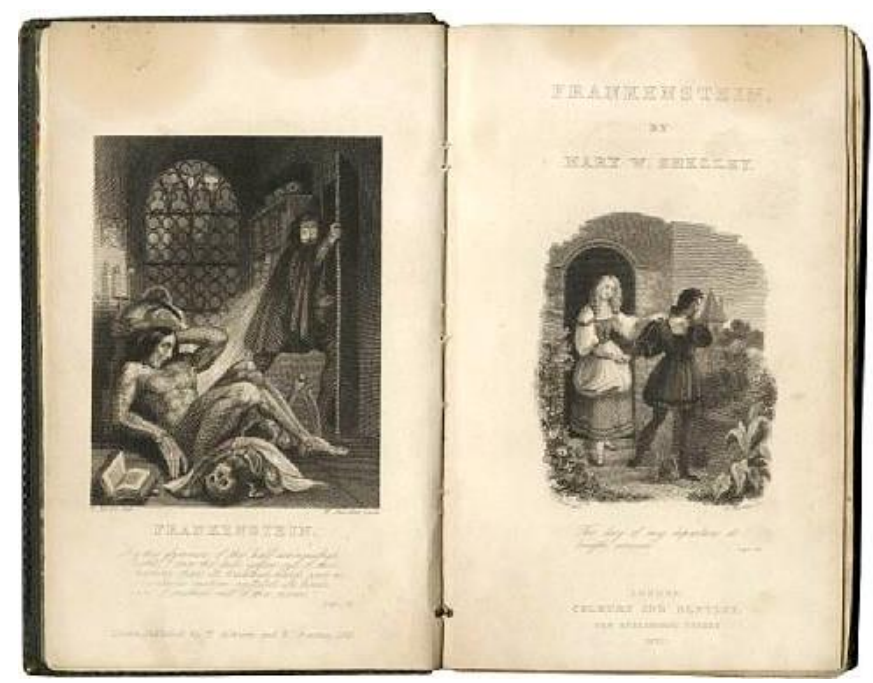

Figura 1: $3^{\mathrm{a}}$ edição da obra Frankenstein (1831), ilustração de Theodor von Holst. ${ }^{6}$

Na produção cinematográfica Frankenstein de Mary Shelley, lançado em 1994 (figura 2), a trama possui o mesmo enredo do livro sendo mais explorados os fatos científicos da época, mostrando cenários onde se desenvolvia a ciência naquele contexto, além de explorar, de forma áudio-visual, os passos do médico Victor Frankenstein para chegar na criatura que desafiava os limites da mortalidade.

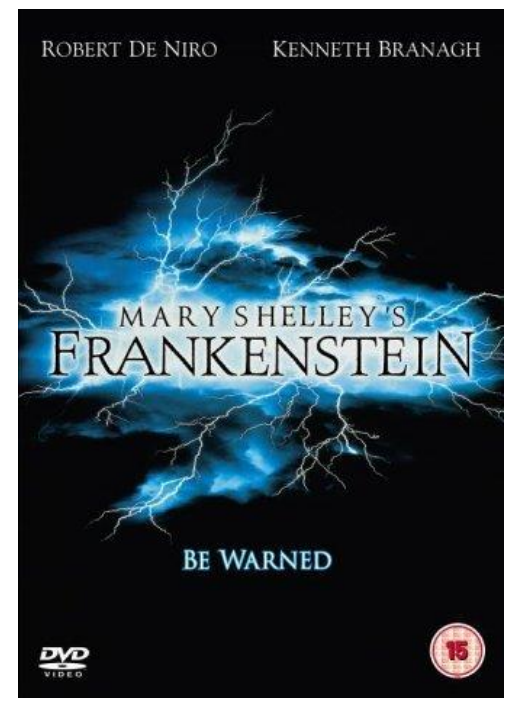

Figura 2: Capa do DVD do filme Frankenstein na versão em inglês de $1994{ }^{7}$

\footnotetext{
${ }^{5}$ L. R. Mayer, A Teacher's Guide to the Signet Classics Edition of Mary Shelley's Frankenstein (New York: Penguin, 2009), http://www.penguin.com/static/pdf/teachersguides/Frankenstein.pdf (acessado em 31 de março de 2016).

${ }^{6}$ Fonte: Book-Hesthete, http://book-aesthete.tumblr.com/search/frankenstein.

${ }^{7}$ Fonte: IMDb, http://www.imdb.com/media/rm3397098496/tt0109836?ref_=tt_ov_i.
} 
Tanto o livro como o filme são obras riquíssimas no sentindo de compreender como a Ciência era tratada entre os cientistas e a sociedade do início do século XIX, e expõe como os conhecimentos vinham progredindo, tornando essas obras valiosos recursos para estudos de História da Ciência dentro do Ensino de Ciências. Segundo Quintal \& Guerra ${ }^{8}$, a abordagem histórica auxilia no aprendizado dos conteúdos científicos, como também no próprio processo de desenvolvimento cognitivo individual do aluno.

\section{A ClÊNCIA REPRESENTADA EM FranKEnStein}

Durante todo o filme os conhecimentos científicos são expostos como pano de fundo para a trama que se desenvolve, mostrando a diversidade de descobertas já realizadas até aquele período e como estas foram importantes para o desenvolvimento das teorias de Victor Frankenstein. A produção cinematográfica possui um caráter diferencial frente a tantas outras, em virtude de estar baseada em uma obra literária, cuja autora foi contemporânea das grandes descobertas científicas e conhecia de perto muitos dos cientistas. Tais elementos devem ser explorados pelos professores tanto para seu próprio conhecimento como ainda para fazer seus alunos compreenderem como surgiram as teorias e em qual contexto estavam inseridos, como relata um monitor.

Além da figura do próprio Victor Frankenstein, como um apaixonado pelo conhecimento científico e o fazer Ciência, são encontrados vários outros elementos relacionados à Ciência durante as cenas do filme, tais como: as experiências realizadas pelo cientista Galvani (Corrente elétrica); experimento de Benjamim Franklin (Para-raios); conservação de matéria prima utilizando o gelo; líquido amniótico como principal fonte de matéria prima para sua experiência, os paradigmas científicos (observado na cena em que o Sr. Frankenstein está na Universidade de Ingolstadt discutindo com o professor Krempe sobre alguns embates filosóficos e até mesmo teológicos que afetam na produção científica, as ideias revolucionárias do protagonista (a busca pela possibilidade de derrotar a morte e a doença, a fim de permitir que todos possam ter uma vida saudável. (Monitor B)

Outro fator que o torna interessante, do ponto de vista da ciência, são as abordagens científicas nele presentes e como elas aparecem conforme o passar do tempo, isso subsidia ao professor elementos suficientes para levantar discussões sobre como os conhecimentos foram

\footnotetext{
8 J. R. Quintal \& A. Guerra, "A História da Ciência no Processo Ensino-Aprendizagem," Física na Escola 10, n 1 (2009),
} http://www.sbfisica.org.br/fne/Vol10/Num1/a04.pdf (acessado em 31 de março de 2016). 


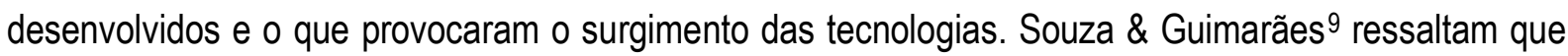
os filmes possuem um papel fundamental no sentido de divulgar e disseminar os conceitos científicos, conferindo à Ciência um caráter multidisciplinar e contextualizado. Nascimento et al. ${ }^{10}$ pontua a necessidade de se trabalhar com filmes nas escolas por ser um recurso midiático riquíssimo em conhecimento, o que contribui para a aprendizagem dos educandos.

\section{AS PROdUÇÕES CINEMATOGRÁFICAS COMO UMA FERRAMENTA DE ENSINO NO ENSINO DE CIÊNCIAS}

O uso de mídias áudio-visuais sempre foi um recurso usado na educação para fins didáticos, mais corriqueiramente nas disciplinas de literatura e história, sendo usados quase que integralmente para interpretar ou analisar algum fato ou texto. Nas aulas de ciências são utilizados, na grande maioria, vídeos didáticos direcionados à aprendizagem de um determinado conteúdo e as abordagens cinematográficas raramente adotadas pelos professores de ciências; isso na maioria das vezes consolida uma visão de que a ciência não teve nenhuma importância para o desenvolvimento da sociedade.

Podemos demonstrar como era feita a ciência naquela época, retratando a sociedade, avanços tecnológicos, os cientistas e suas teorias, como era feita a experimentação, os materiais usados nas experimentações, e o progresso do conhecimento. Podendo-se fazer relação com a situação atual da ciência e também através da visualização destes feitos, pode-se quebrar paradigmas que os alunos criam sobre a ciência. (Monitor $\mathrm{C}$ )

As produções cinematográficas são ferramentas que atraem os alunos devido a sua dinamicidade, o que torna o ensino mais encantador, facilitando o entendimento do processo de construção do conhecimento das ciências. A utilização de filmes às aulas vinculados às atividades motiva e induz 0 estudante ao questionamento, tornando-se importante instrumento para compreender a visão em relação aos cientistas e como se propagou a ciência em determinado período histórico sendo retratado ao filme. Além disso, instiga o indivíduo a formação do pensamento crítico com desrespeito as obras. (Monitor $\mathrm{D}$ )

\footnotetext{
${ }^{9}$ Souza \& Guimarães, "Filmes nas Salas de Aula," 101.

${ }^{10}$ R. C. Nascimento et al., "Utilização de Filmes Comerciais no Ensino de Ciências," in Anais do VI Encontro Regional Sul de Ensino de Biologia, Santo Ânjelo, RS (2013), http://santoangelo.uri.br/erebiosul2013/anais/wpcontent/uploads/2013/07/poster/13713_298_RENATA_CALIMAN_DO_NASCIMENTO.pdf (acessado em 28 de março de 2016).
} 
Por meio desses relatos, nota-se uma expansão do olhar sobre esse tipo de recurso, por ser algo acessivel torna-se uma ferramenta útil e construtiva quando bem trabalhada. Trabalhar com textos inicialmente com os alunos pode não ser a melhor maneira de sensibilizá-los sobre a História da Ciência caso não estejam muito bem estruturados e com objetivos bem claros ao olhar dos alunos.

Uma abordagem visual pode vir a ser mais eficiente, no sentido de conseguir fornecer ao aluno um rosto, uma voz e um estilo ao cientista que desenvolveu determinado conhecimento, servindo, assim, como base para os demais que ele encontra nos livros. Segundo Santos \& Gebara ${ }^{11}$, os filmes podem trabalhar emoções, valores e experiências por meio de distintas linguagens: visual, oral, musical e escrita, e sendo empregados de maneira adequada possibilita a aprendizagem. EHöttecke et al12 enfatiza que os problemas, ações e ideias dos cientistas do passado fornecem um guia estruturado e centrado para as atividades dos estudantes, em que os mesmos podem atuar até de forma similar aos pesquisadores.

\section{OS FILMES COMO FERRAMENTA DE ENSINO DA HISTÓRIA DA CIÊNCIA}

A ciência costuma ser retratada em sala de aula como um tipo de conhecimento promovido por poucos e com nível intelectual elevado e, mesmo inconscientemente, o próprio professor acaba passando tal pensamento em suas aulas. Abordar a História da Ciência em suas aulas permite que trabalhe a construção do conhecimento e suas etapas até a sua aplicação em nosso cotidiano. Um dos elementos que vem auxiliar o professor na abordagem histórica de construção dos conhecimentos científicos são os filmes, por serem carregados de imagens e falas que dão vida à figura do cientista. No caso de Frankenstein, o filme consegue traçar um perfil da imagem dos cientistas e do contexto que estavam inseridos, além de expor como a ciência era tratada naquele período, como relatam alguns monitores.

Dos diversos pontos positivos que o filme possui para que seja abordada a História da Ciência, entre estes se destaca por ser um filme que retrata a Ciência do século XVII destacando vários pontos específicos de estudos científicos da época, no entanto, a questão da ética diante a Vida ainda é algo tão contemporâneo. As discussões que permeiam no meio social e científico sobre a Vida é algo que pode ser discutido diante diversas áreas de estudo. (Monitor A)

\footnotetext{
11 J. N Santos \& M. J. F. Gebara, "Ensino de Ciências Naturais: O Filme como Recurso Didático nas Aulas de Ecologia," in Anais do IV Simpósio Nacional de Ensino de Ciências e Tecnologia, Ponta Grossa, PR, (2014), http://sinect.com.br/anais2014/anais2014/artigos/ensino-de-ciencias/01409607480.pdf (acessado em 26 de março de 2016).

12 D. Höttecke, A. Henke, \& F. Riess, "Implementing History and Philosophy in Science Teaching: Strategies, Methods, Results and Experiences from the European HIPST Project," Science \&Education 21, no 9 (2012): 1233-1261, http://www.bu.edu/hpsscied/files/2012/10/H\%C3\%B6ttecke-HPS-Implementing-History-and-Philosophy-in-Science-Teaching-Strategies-Methods-Results.pdf (acessado em 30 de março de 2016).
} 
Por ser um filme que retrata um contexto histórico, mais especificamente sobre as descobertas da medicina da época e como as ciências principalmente a química e física explicavam os fenômenos ocorrentes e faz isso respeitando as limitações do dado momento, ou seja, o filme Frankenstein mantém a originalidade da obra de Mary Shelley, isso é fundamental para que o aluno possa de fato conhecer os elementos utilizados anteriormente pelas ciências, evitando assim elementos e cenas fantasiosas, diferenciando-se de outras obras cinematográficas que moldam alguns elementos de acordo com as atuais tecnologias. (Monitor $\mathrm{D}$ )

O filme permite levantar uma gama de discussões sobre o fazer ciência, partindo do processo de construção do conhecimento, assim como as consequências positivas e negativas que surgiram com as novas descobertas e como elas afetaram os cientistas e a sociedade. Outro fator que pode ser discutido é o real objetivo da ciência, e como ela pode por muitas vezes ser utilizada para fins destrutivos. $O$ uso desses recursos subsidia ao professor no momento de formar mentes pensantes em sala de aula, pois leva o aluno a questionar fatos atuais e que refletem em seu meio.

Mas para que isso de fato venha a ocorrer não basta somente mostrar o filme, mas trabalhá-lo sob a óptica da interpretação de seus alunos sobre os fatos nele apresentados e compara-los com o que realmente foi ocorrido. Para Kavaleket al13 o Ensino de Química nas escolas deve abordar não só o que a ciência em questão conhece, mas também como se chegou ao conhecimento em questão: época, contexto social, moral, cultural e quais os envolvidos. Santos \& Gebara ${ }^{14}$ discutem que o filme não substitui a mediação do professor, mas leva a uma leitura reflexiva de um determinado tema, com determinado contexto, por meio de sua linguagem característica, de sua manifestação cultural, possibilitando a construção do conhecimento escolar com essa linguagem.

O filme vem auxiliar no sentido de exibir uma imagem concreta dos cientistas que são estudados nas ciências e levantar tópicos que serviram de discussões por todo decorrer da disciplina.

\section{AS PRODUÇÕES CINEMATOGRÁFICAS E AS BARREIRAS QUE IMPEDEM DE SEREM USADAS COMO RECURSO NAS AULAS DE CIÊNCIAS}

São inúmeras as dificuldades encontradas pelos professores de ciências que os impedem de adotarem filmes como recurso didático. A maior de todos é a carência na sua formação para utilizar tal recurso em suas aulas, levando em consideração que a grande maioria dos cursos de licenciatura das universidades são conteudistas, não existe uma preocupação no como se deve ensinar, mas sim no que ensinar, o que deixa o professor de certa maneira despreparado para utilizar os recursos didáticos

13 Kavalek et al., "Filosofia e História da Química," 3.

${ }^{14}$ Santos \& Gebara, "Ensino de Ciências Naturais," 2. 
em suas práticas educacionais. Os monitores relatam vários fatores que, na visão deles, impedem os professores de utilizarem esse tipo de recurso.

A falta de preparação desses profissionais com recursos de multimídia e segundo eles por falta de tempo, pois devem cumprir os conteúdos programáticos para 0 vestibular. Monitor M.

A falta de tempo. Pois os conteúdos ensinados, são todos voltados com o objetivo de aprovações nos vestibulares, e isso acaba meio que forçando o professor excluir algumas metodologias de ensino. (Monitor $\mathrm{H}$ )

A falta de equipamentos, haja vista que algumas escolas públicas ainda não disponibilizam principalmente as do interior, ou ainda, quando há, surgem as falhas técnicas devido a precariedade de manutenção, além disso, muitos profissionais compreendem que o tempo é insuficiente para repassar o conteúdo e apresentar o filme. Outro fator é a não adaptação de alguns docentes com essa ferramenta de aprendizagem, muitos ainda se voltam ao ensino tradicional, propagado através da lousa e pincéis, os quais são essenciais, porém necessitam em alguns momentos de um complemento. (Monitor D)

Há um pensamento entre os professores que o ensino tradicional ainda é a melhor maneira de preparar seus alunos para os exames de vestibulares. Um equívoco, visto que estão usando métodos antigos para uma ação atual, ignorando metodologias que tornam o ensino mais completo. Segundo Souza ${ }^{15}$ o professor deve ter formação e competência para utilizar os recursos didáticos que estão ao seu alcance para construir, juntamente com seus alunos, a assimilação do conteúdo. Santos ${ }^{16}$ ressalta que a produção e uso de recursos didáticos por professores contribui de forma expressiva em sua formação continuada, sobretudo se tal produção não for individual, mas inserida nos espaços de discussão e formação coletivas nas escolas. 0 professor possui consciência dos recursos de que dispõe para lecionar, no entanto, o tipo de formação que teve o faz enveredar por caminhos pouco progressivos.

A dinâmica que o uso de filme proporciona não só direciona o ensino do conteúdo como ainda acelera esse processo, já que o aluno consegue perceber além da sua visão abstrata sobre a ciência.

\footnotetext{
15 S. E. Souza, "O Uso de Recurso Didáticos no Ensino Escolar," in I Encontro de Pesquisa em Educação, IV Jornada de Prática de Ensino, XIII Semana de Pedagogia da UEM: "Infância e Práticas Educativas", ArqMudi 11, Supl. 2 (2007), http://www.dma.ufv.br/downloads/MAT\%20103/2015-I//slides/Rec\%20Didaticos\%20-\%20MAT\%20103\%20-\%202015-II.pdf (acessado em 27 de março de 2016).

${ }^{16}$ M. C. Santos, "A Importância da Produção de Material Didático na Prática Docente," in Anais do VII Congresso Brasileiro de Geógrafos, Vitória, http://www.cbg2014.agb.org.br/resources/anais/1/1404098564_ARQUIVO_AlmportanciadaProducaodeMaterialDidaticonaPraticaDocente. pdf (acessado em 26 de março de 2016).
} 


\section{CONSIDERAÇÕES FINAIS}

Por ser um mediador dos conhecimentos científicos, o professor de ciências precisa criar e ter ao seu alcance recursos e métodos de ensino que possibilitem realizar o processo de transmissão e criação do conhecimento com seus alunos. A História da Ciência pode se tornar um método para mostrar aos seus alunos os fundamentos dos conhecimentos que presenciam tanto em sala de aula como no seu cotidiano. E, de fato, a utilização de filmes que abordem elementos que representem o desenvolvimento da Ciência pode ser um excelente recurso para que o professor introduza os conteúdos. Mas, como relatam os graduandos, ainda há falta de formação para que o licenciado se sinta capaz de desempenhar esse papel de mediador. No entanto, criar alternativas como o uso de mídias e deixá-las acessíveis aos professores contribui para que os mesmos interajam de forma mais detalhada em sua área de conhecimento e consigam desenvolver meios para estruturar o Ensino de Ciências nas escolas.

\section{SOBRE OS AUTORES:}

André Silva dos Reis

Mestrando do Programa de Pós-graduação em Química, Universidade Federaldo Pará. Membro do Grupo de Pesquisa em Ciência, Tecnologia, Meio Ambiente e Educação Não Formal do Centro de Ciências e Planetário do Pará.

\section{Maria Dulcimar de Brito Silva}

Mestre em Química de Produtos Naturais. Professora do Curso de Licenciatura Plena em Ciências Naturais da Universidade do Estado do Pará. Pesquisadora do Grupo de Pesquisa em Ciência, Tecnologia, Meio Ambiente e Educação Não Formal do Centro de Ciências e Planetário do Pará.

Artigo recebido em 29 de agosto de 2016 Aceito para publicação em 02 de janeiro de 2017 